\title{
ORGANİK ATIKLARIN YAPI MALZEMESİ OLARAK KULLANABİLİRLİĞİNİN ARAŞTIRILMASI
}

\author{
İsmail DEMİ**, Muhammet ELMALI
}

Afyon Kocatepe Üniversitesi, Mühendislik Fakültesi, İnşaat Mühendisliği Bölümü

\begin{tabular}{l} 
Anahtar Kelimeler \\
\hline Organik Atıklar, \\
Geri Dönüşü ve Geri \\
Kazanım, \\
Yapı Malzemeleri, \\
Çimento ve Beton Katkıları, \\
Cevrenin Koruması.
\end{tabular}

$\ddot{0 ̈ z}$

Küresel ısınmayla birlikte çevresel sorunlara olan ilgi son on yıllarda giderek artmıştır. Küresel ısınmanın en önemli nedeni sanayileşme ile birlikte giderek artan $\mathrm{CO}_{2}$ salınımıdır. Sanayileşme ile birlikte gelişen kentlerin altyapı ve üst yapılarının inșasında ana girdi beton ve buna bağlı olarak çimento üretimi gelmektedir. Çimento fabrikalarında, üretim prosesinde ortaya çıkan $\mathrm{CO}_{2}$ ve partiküller hava kirleticileri arasında ilk sıralarda yer almakta, büyük oranda atmosfere sera gazı salınımı yapmaktadır. Küreselleşen Dünyada sanayileşme ve kentleşmenin etkisiyle birlikte kaynakların aşırı kullanımı ve artan tüketim sonucu atık miktarı da sürekli artış göstermektedir. Gittikçe katlanarak büyümekte olan atık sorunu; toplumu, aileyi ve bireyi etkilemekte hayat kalitesini olumsuz etkilemektedir. Atık sorununu çözmek için, toplanan materyallerin yeniden işlenmesi, üretimde kullanılması olan geri dönüşüm, bir zorunluluk olarak günümüz Dünyasında önemli yer tutar. Organik atıklar arasında: tarımsal atıklar, fıstık kabuğu, fındık kabuğu, pirinç kabuğu, şeker kamışı, palmiye yağı, saman, çay artıkları, pamuk sapı, ayçiçeği sapı, mısır koçanı, pamuk ve tekstil atıkları, odun lifleri vb yer almaktadır. Bu çalışmada, organik kökenli atıkların yapı malzemeleri üretiminde kullanılabilirliği üzerine yapılan çalışmalar değerlendirilmiştir. Çalışmada, birçok atık türünden (tarım, evsel, tıbbi, sanayi, santral, vb.) organik kökenli atıklar seçilerek, yapı malzemesi üretiminde tekrar kullanılması veya geri dönüșümü ile kaynak kullanımının ve bertaraf oranını azaltarak çevrenin korunmasına katkı sağlanabileceği ortaya konmuştur.

\section{INVESTIGATION OF THE USABILITY OF ORGANIC WASTES AS A BUILDING MATERIAL}

\begin{tabular}{l}
\hline Keywords \\
\hline Organic Wastes, \\
Recycling and Recovery, \\
Construction Materials, \\
Cement and Concrete \\
Additives, \\
Environmental Protection.
\end{tabular}

Environmental Protection.

\begin{abstract}
With global warming, the interest in environmental problems has been increased steadily in the last decades. The most important cause of global warming is the increasingly $\mathrm{CO}_{2}$ emission with industrialization. The main input in the construction of the infrastructure and superstructure of the cities that developed with the industrialization is concrete and accordingly cement production. In cement factories, emerging in the production process $\mathrm{CO}_{2}$ and particles are among the top air pollutants, emitting greenhouse gases to the atmosphere to a large extent. With the effect of industrialization and urbanization, the amount of waste increases continuously as a result of excessive use of resources and increasing consumption in the globalizing world. Waste problem that is growing exponentially; It has been affects the society, family and individual, and its negatively affects the quality of life. To solve the waste problem, recycling, which is the reprocessing of collected materials and their use in production, has an important mission in today's world as a necessity. Organic waste includes: agricultural wastes, peanut shell, nutshell, rice husk, sugar cane, palm oil, straw, tea scraps, cotton stalk, sunflower stalk, corn cob, cotton and textile wastes, wood fibers, etc. In this study, studies on the usability of organic wastes in the production of building materials were evaluated. In the study, it has been revealed that by selecting organic origin wastes, reusing or recycling in building material production, it has been shown that it can contribute to the protection of the environment by reducing the rate of resource use and disposal.
\end{abstract}




\begin{tabular}{|c|c|c|}
\hline \multicolumn{3}{|l|}{ Alıntı / Cite } \\
\hline \multicolumn{3}{|c|}{$\begin{array}{l}\text { Demir, İ., Elmalı, M., (2020). Organik Atıkların Yapı Malzemesi Olarak Kullanabilirliğinin Araştırılması, } \\
\text { Mühendislik Bilimleri ve Tasarım Dergisi, 8(4),1303-1311. }\end{array}$} \\
\hline Yazar Kimliği / Author ID (ORCID Number) & Makale Süreci / Article Process & \\
\hline $\begin{array}{l}\text { İ. Demir, 0000-0001-8493-0309 } \\
\text { M. Elmall, 0000-0003-2281-6126 }\end{array}$ & $\begin{array}{l}\text { Başvuru Tarihi / Submission Date } \\
\text { Revizyon Tarihi / Revision Date } \\
\text { Kabul Tarihi / Accepted Date } \\
\text { Yayım Tarihi / Published Date }\end{array}$ & \begin{tabular}{|l|}
17.08 .2020 \\
11.10 .2020 \\
19.10 .2020 \\
25.12 .2020
\end{tabular} \\
\hline
\end{tabular}

\section{Giriş (Introduction)}

Küreselleşen Dünyada sanayileșme ve kentleşmenin ihtiyacı olan doğal kaynakların aşırı ve bilinçsiz kullanımı sonucu atık miktarları sürekli artış eğimline sahiptir. Küresel ölçekte ortaya çıkan atık sorunu; toplumu, aileyi ve bireyi etkilemektedir. Daha önce toplanan materyallerin yeniden işlenmesi, üretilmesi ve kullanılması olan geri dönüşüm, günümüz Dünyasında önemli yer tutmaktadır (Gündüzalp ve Güven, 2016). Sanayi Devrimi ile üretimdeki artış, teknolojinin gelişmesi ve hızla yaygınlaşması, yaşam standardının yükseltilmesi hedefleri atmosferde sera etkisine yol açan gazların artmasına neden olmuştur. Özellikle İkinci Dünya savaşından sonra sera gazlarındaki hızlı arştın yol açtığı küresel ısınmanın sonucu olarak insan, bitki ve hayvan türlerinin yaşamını tehdit eden doğal felaketlerde artış kaydedilmiştir. Yirminci yüzyılın son çeyreğinden günümüze kadar gelen süreçte endüstri alanındaki gelișmeler, doğal hammadde kaynaklarının ve fosil yakıtların aşırı tüketimi sonucu sera gazları salınımının artmasına ve buna bağlı olarak küresel ısınmanın giderek artışına yol açmıştır. Sanayileşmenin üretim aşamasında doğrudan $\mathrm{CO}_{2}$ salınımına neden olması dıșında, kullanılan hammaddelerden arda kalan atıklarda çevre için büyük sorun oluşturmaktadır. Kil, kum, taş, çakıl, çimento, tuğla, fayans, boya, kereste ve çelik gibi geleneksel malzemeler inşaat sektöründe ana yapı bileşenleri olarak kullanılmaktadır. Bu malzemelerin üretiminde mevcut doğal kaynaklar kullanılmaktadır. İnşaat sektörü doğal kaynak kullanımının büyüklüğü ve sürekliliği nedeniyle doğal çevreye olan etkisi bakımından ayırt edici özelliğe sahiptir. Çok fazla çeşide sahip yapı malzemelerinin üretimi sırasında karbon monoksit konsantrasyonu, sülfür oksitler, azot oksitler ve süspansiyon halindeki parçacık maddeler atmosfere yayılmaktadır (Pappua vd., 2007). Nüfus artışı, artan kentleşme, teknolojik yenilikler nedeniyle yükselen yaşam standartları, endüstri, madencilik, evsel ve tarımsal faaliyetlerden kaynaklanan katı atıkların miktarının ve çeşitliliğinin artmasına katkıda bulunmuştur. Küresel olarak 2002 yılında tahmini atık üretimi miktarı 12 milyar ton olup, bunun 11 milyar tonu endüstriyel atık ve 1,6 milyar tonu kentsel katı atıklardır. 2025 yılına kadar yılda yaklaşık 19 milyar ton katı atık üretilmesi beklenmektedir (Yoshizawa vd., 2004). Sanayi hammaddelerinin sınırlı doğal kaynaklar olduğu, giderek artan nüfusun tüketimi daha çok artıracağı da dikkate alınarak, çoğu hammadde kaynaklarının önümüzde ki yüzylllarda tükeneceği beklenmektedir. Bu nedenle hem atık azaltma hem de hammadde kaynağı olabilmesi açısından birçok atık türünden organik kökenli, yenilebilir, çevreye ve sağlığa zararsız tarım atıklarının inşaat sektöründe kullanılabilirliği önem kazanmıştır. Bu çalışmada organik kökenli atıkların yapı malzemeleri üretiminde kullanılabilirliği ile ilgili çalışmalar derlenerek incelenmiştir. Organik kökenli atıkların üretim prosesinde önemli bir kullanım potansiyeli olduğu ve çeşitli çevre dostu yapı malzemelerinin üretilebileceği ortaya konmuştur.

Biyokütle Türkiye açısından önemli bir potansiyele sahiptir ve bu anlamda biyokütle odaklı enerji politikalarının geliştirilmesi Türkiye'de sürdürülebilir, yerli, ucuz ve temiz enerji üretiminde önemli katkı sağlayabilir (Gürel 2020). Tarımsal atıklar, tarımsal üretim ve meyve, sebze, et, kümes hayvancılığı, süt ürünleri ve ekinler gibi ham tarımsal ürünlerin ilk prosesinden arta kalan atıklar olarak tanımlanmaktadır (Öner 2109). Türkiye 'de dikkate değer miktarda organik kökenli (tarım) atıkları ortaya çıkmaktadır (Tablo 1).

Tablo 1. Türkiye'de potansiyel tarım atıklar (Bolat, 2005) (Potential agricultural waste in Turkey)

\begin{tabular}{|l|c|}
\hline TARIMSAL KALINTILAR & YILLIK ÜRETIM (MILYON TON) \\
\hline Ayçiçeği sapları & 2.7 \\
\hline Buğday sapları & 26.4 \\
\hline Arpa sapları & 13.5 \\
\hline Mısır sapları & 4.2 \\
\hline Pamuk sapı ve koza & 2.9 \\
\hline Şeker pancarı sapları & 2.3 \\
\hline Fındık kabukları & 0.8 \\
\hline Yulaf sapları & 0.5 \\
\hline Çavdar sapları & 0.4 \\
\hline
\end{tabular}




\section{Organik Atıkların Beton Üretiminde kullanılabilirliği (Usability of Organic Wastes in Concrete Production)}

İnşaat sektörünün ana girdilerinin başında çimento gelmekte olup, çimento üretimi 2017 yllında Dünyada 4.1 Milyar ton, Türkiye'de ise 79.9 milyon ton olarak gerçekleşmiştir (Çim. Sek. Rap., 2018). İnşaat sektöründe, çimento üretimi esnasında $\mathrm{CO}_{2}$ salınımından dolayı çimento fabrikaları, partiküller hava kirleticileri arasında ilk sırada yer almaktadır. Çimento imalatı sırasında klinikleri yakmak için kullanılan döner fırınlarda oluşan gazlar (SO, CO, NO), öğütülmüş kireçtaşı ve çimento tozları bu endüstride çevreye yayılan en önemli kirleticilerdir. Çimento fabrikalarının bilinen bu etkilerinin yanı sıra diğer bir önemli etkisi de çevreye kadmiyum elementi yaymasıdır. Çevreye yayılan kadmiyum toprakta birikmekte, buradan bitkilere geçip daha sonra besin zinciri ile insanlar tarafından tüketilmektedir (Kartalkanat, 2010). Talepteki artış ile birlikte artan çimento üretimi, hem atmosfer hem de çevre için risk olușturmaktadır. Üretim ve tüketim faaliyetleri sonucu ortaya çıan organik atıkların uygun prosesler ile çimento ile ikame edilmesi sonucu çimentoya duyulan ihtiyaç azaltılabilir ve üretim miktarı düşürülebilir. Ancak organik atıklarla üretilecek betonun mekanik, fiziksel ve reolojik özellikleri normal Portand çimentosu (PÇ) ile üretilen betonundan farklı olmamalıdır.

Organik kökenli atıklarla yapılan araştırmalarda, Alabadan vd. (2005) PÇ, Bambara Yerfıstı̆̆ı Kabuğu Külü (YKK) ile ikame edilerek üretilen beton incelenmiştir. Kimyasal analizi çimentoya çok benzeyen YKK, ağırlıkça çimento yerine $\% 0$ - \%50 arasında oranlarda ikame edilmiştir. Üretilen betonunun mukavemeti, kür süresi ile artmıș, fakat artan YKK yüzdesi ile azalmıştır. 28 günde kontrol numunesi $31.24 \mathrm{~N} / \mathrm{mm}^{2}$ mukavemete ulaşırken, kül ile en yüksek mukavemet $\left(20.68 \mathrm{~N} / \mathrm{mm}^{2}\right) \% 10$ kül ikamesi ile elde edilmiștir. Buari vd. (2013) PC'nin YKK ile \%0-\%20 arasında oranlarda ikame edilmesini araştırmıştır. Çalışmada \%10 YKK ikamesinin en iyi mekanik sonuçları verdiği görülmüştür. Nwofor ve Sule (2012) benzer bir çalışmada Nijarya yer fistığı kabuğu külü kullanımını araştırmıştır. PC \%0-\%40 arasında oranlarda ikame edilmiştir. Sonuçlar, YKK ile ikame yüzdesi arttıkça yoğunluk ve basınç mukavemetinde bir azalma göstermiştir. Her üç çalışmada da çimentonun beton üretiminde YKK ile ikame edilmesinin \%10'u geçmeyecek şekilde mümkün olduğunu göstermiştir.

Pirinç kabuğu, pirinç üreten ülkelerde bol miktarda bulunan pirinç tanesinin doğal bir dış kabuğudur. Bir ton pirinçten yaklaşı $200 \mathrm{~kg}$ kabuk ve yakma sürecinden sonra bunun da yaklaşı \%18-20'si kül olarak ortaya çıkar (Khan vd., 2012; Le vd., 2014; Aprianti vd., 2015;). Tarım atı̆̆ı olan ve süper puzolan olduğu bilinen pirinç kabuğu külü (PK) beton için sıkça kullanılan bir mineral katkıdır (RILEM, 2013; Mehta ve Folliard, 1992). Çimentolu ürünlerin davranışı PK'nın kaynağına göre değișir (James ve Rao, 1986; Malhotra ve Mehta, 1996). Akeke vd. (2013) PC, PK ile kütlece \%10-25 oranlarında ikame edilmiştir. Sonuçlar; üretilen betonların 33-38.4 N/mm² arasında değişen basınç ve 2.4-3 N/ $\mathrm{mm}^{2}$ arasında değişen çekme mukavemetine sahip olduğunu göstermiştir. Benzer bir çalışma yapan, Kishore vd. (2011) PC, PK ile ikame edilerek yüksek mukavemetli beton üretmeyi çalışmışlardır. Sonuçlar; kütlece \%10 ikame betonların 28 günde oldukça yüksek mekanik sonuçlar göstermiştir. Sensale (2005) yaptığı çalışmada, Uruguay'daki bir çeltik öğütme endüstrisinden elde ettiği PK ile ABD'den kontrollü yakma ile üretilen PK karşılaştırması ve 91 günlük basınç dayanımı üzerine araştırma yapmıştır. İki farklı PK, PÇ ile kütlece \%10 ve \%20 oranlarında ikame edilmiş ve üç farklı su/çimento oranı $(0.50,0.40$ ve 0.32$)$ kullanılmıştır. Atık PK'nın erken yaşlarda basınç dayanımı üzerinde olumlu bir etki sağladığı, ancak kontrollü yakma ile üretilen PK ile betonların 91 günlük basınç dayanımı çok daha yüksek çıkmıştır. Hava geçirgenliğinin sonuçlarında ise her iki tür PK'lı betonlar puzolanik etki nedeniyle kontrol numunesine göre daha yüksek performans göstermiştir. Saraswathy ve Song (2007) PK ikameli betonunun korozyon performansını araştırmıştır. Bu amaçla üretilen betonların korozyon performansı açık devre potansiyel ölçümleri, hızlı klorür iyonu geçirgenlik testi ve baskı gerilimi testi ile değerlendirilmiștir. Sonuçlar, PK'nın \%30'a kadar ikame edilmesinin, klorür geçirgenliğini azalttığı, mukavemet ve korozyon direnci özelliklerini geliștirdiğini göstermiştir. PK ile yapılan çalışmalar, PK'nın uygun değiştirme oranlarında yapısal beton olarak kullanılabileceğini kanıtlanmıştır. PK'nın reaktivitesi, yüksek amorf silika içeriğine ve parçacıkların gözenekli yapısı sayesinde çok geniş yüzey alanına sahip olmasına, diğer anlamda materyalin inceliğinin artması atfedilmektedir (Mehta, 1978; Mehtra ve Folliard, 1992; Cook, 1984; James ve Rao, 1986; Kraiwood vd., 2001; Paya vd., 1995; Paya vd., 1997).

Şeker kamışı küspesi, şeker rafine endüstrisinin lifli atık ürünüdür. Yashwanth ve Nagarjuna (2016) Çimento ikamesi olarak şeker kamışı küspesi külü (ŞKK) ve uçucu kül (UK) kullanarak beton üzerindeki etkisi incelenmiştir. Çalışmada, ŞKK ve UK ağırlıkça çimento ile \%0, \%5, \%10, \%15 ve \%20 oranında değiştirilmiştir. Normal beton ile karşılaştırıldığında ŞK ve UK ikamesi betonunun işlenebilirliğini artırmış ve ikame oranı arttıkça betonun basınç dayanımının \%15'e kadar arttığı belirlenmiştir. Sreenivasulu vd. (2018) agrega olarak granit tozu ve ŞKK, kütlece $\% 0, \% 5, \% 10, \% 15$ ve \%20 arasında çimento ile ikame edilerek beton üretmişlerdir. Sonuç olarak ŞKK'nin \%10'a kadar çimento ile değiştirilmesinin uygun olacağı önerilmiştir. Bu çalışmalarda ŞKK'nın çimento ikamesi olarak belli oranlarda kullanabileceği önerilmiştir. 
Palm yağı olarak da bilenen Palmiye yağı, üretiminin bir yan ürünü olan palmiye yağı yakıt külü (PYK), atık depolama sahalarında bertaraf edilmektedir. Konu ile ilgili araştırmacılar PYK'nın beton üretiminde kullanabilirliğini incelemişlerdir. Tangchirapat vd. (2007) PYK, çimento ile üç farklı tipi incelikte ağırlıkça \%10, $\% 20, \% 30$ ve \%40 oranlarında değiștirilerek puzolanik özelliği ve betonun priz süresi, basınç dayanımı ve sülfat atağına bağlı genleşme gibi özellikleri araştırılmıştır. Sonuçlar, betonlarda PYK kullanımının priz sürelerinde gecikmeye neden olduğunu göstermiştir. Beton örneklerin 56 günlük dayanımları PYK'nın mükemmel bir puzolanik malzeme olduğunu ve $\% 20$ ve $\% 30$ oranlarında betonda çimento yerine kullanabileceğini göstermiştir. Chindaprasirt vd. (2007) PYK ve PK ağırlıkça \%20, \%40, \% 55 oranlarında çimento yerine kullanılarak üretilen betonların basınç dayanımı ve su geçirgenliği araştırılmıştır. Çimentonun her iki malzeme ile değiştirilmesi, işlenebilirliği azaltmış ve daha fazla su ihtiyacı göstermiştir. Test sonuçları; \%20 oranında PYK veya PK içeren betonların basınç dayanımları PÇ ile üretilen betonun basınç dayanımına yakın sonuçlar göstermiş, su geçirgenliği normal betondan daha düşük çıkmıştır. İçerisinde \%40 oranında PYK veya PK bulunan betonun basınç dayanımları PÇ ile üretilen betondan daha düşük olmasına rağmen, su geçirgenliği normal betondan daha düşüktür. PYK veya PK oranı \%55' çıktığında betonun test sonuçları yeterli değerlere ulaşamamıştır. Pone vd. (2018) PYK, çimento ile ağırlıkça \%2.5, \%5, \%10, \%15 ve \%20 oranlarında değiştirilerek ve 0.5 su/çimento oranı sabit tutularak üretilen betonların erken yaşlarda dayanım özellikleri araştırılmıştır. Sonuçlar, \%2.5 ve \%5 oranında PYK içeren numunelerin, kontrole kıyasla daha yüksek erken basınç mukavemeti gösterdiği belirlenmiştir. Yapılan çalışmalar, PKY'nin puzolan katkı olarak beton üretiminde kullanılabileceğini göstermiştir. Binici vd. (2008) mineral katkı maddesi olarak mısır koçanı (MK), buğday samanı (BS) ve çınar ağacı yaprak külü (ÇK) kullanılarak beton dayanıklılı̆̆ı üzerine etkilerini incelemişlerdir. İnce agrega olarak \%2, \%4 ve $\% 6$ oranlarında ikame edilmiş üç seri halinde on beton karışımı üretilerek araştırılmıştır. Betonun dayanıklılığını belirlemek için, 7, 28, 90, 180 gün normal kür ve 18 ay sodyum sülfat çözeltisi kürü uygulanan numunelerin basınç dayanımları, aşınma direnci ve su geçirgenliği araştırılmıştır. Test sonuçları, MK, BS ve ÇK ilavesinin geleneksel betona kıyasla iyi işlenebilirlik ve aşınma direnci sağladığını göstermiştir. Ayrıca, MK, BS ve ÇK katkılarının beton örneklerin sodyum sülfat direncinde önemli bir artış sağladığını göstermiștir. Çalıșma sonucuna göre, dayanıklı beton üretimi için MK, BS ve ÇK katkılı beton üretimi tavsiye edilmiştir. Demirbaș ve Aslan (1998) betona çay atığl, öğütülmüş fındıkkabuğu, ladin, kayın ağacı atıkları karıştırarak mekanik özelliklerini incelenmiştir. Öğütülmüş fındıkkabuğu ve kayın ağacının PÇ için katkı maddesi veya kısmi ikame olarak kullanılabileceği öne sürülmüştür. Bununla birlikte, çay atıklarının betonun mekanik özelliklerine zarar vermiştir. Baluch vd. (1978) yaptıkları çalışmada, çelik elyaf takviyeli çimento harcının kırılma direncini belirme için önerilene benzer bir model kullanarak, sisal elyaf takviyeli çimento harcının mukavemetini belirlemeyi amaçlamıştır. Çalışmada, sisal elyaf takviyesinin çimento harcının basınç mukavemetini geliştirdiği görülmüştür.

\section{Yalıtım Malzemeleri Üretiminde Kullanılabilirliği (Usability in Insulation Materials Production)}

Günümüzde, inşaat sektöründe enerji tasarruflu ve çevreci yeșil binalara olan ilgi hızla artmaktadır. Yeşil binaların inşasında, enerji tasarrufu sağlayan yalıtım malzemelerinin organik malzemeler ve atıklardan üretilebilmesi önemli bir araştırma alanı olmuştur. Bu amaçla; Khedari vd. (2004) tavan ve duvar yalıtım malzemesi olarak kullanıldığında enerji tasarrufu için etkili olan, düşük ısı iletkenliğine sahip Durian kabuğu ve Hindistan cevizi elyafı karışımından yeni ve düşük maliyetli yonga levha geliştirmiştir. Durian kabuğu ve hindistan cevizi elyafı ağırlıkça 10/90 karışım oranı ile üretilen levhanın $856 \mathrm{~kg} / \mathrm{m}^{3}$ yoğunluk, $0.1342 \mathrm{~W} / \mathrm{mK}$ isıl iletkenlik, 21.867 $\mathrm{kgf} / \mathrm{cm}^{2}$ elastikiyet modülü, \%6.22 nem içeriği değerlerine sahip olduğu görülmüștür. Xu vd. (2004) kenaf çekirdeğinden düşük yoğunluklu, bağlayıcısız, formaldehit içermeyen yonga levha geliştirmiştir. Levhalar, buhar enjeksiyon presleme (buhar basıncı 1.0 MPa, buhar süresi 7-10 dakika) kullanılarak başarılı bir şekilde bağ yapısı gelişmiştir. 10 dakikalık buhar etkisi ile $200 \mathrm{~kg} / \mathrm{m}^{3}$ yoğunluktaki yonga levhaların ısı iletkenliği, taş yününe benzer değerler göstermiştir. Zhou vd. (2010) pamuk sapı elyafından bağlayıcısız, yüksek frekanslı sıcak presleme kullanılarak yonga levhalar geliștirilmiştir. Yoğunluğu $150-450 \mathrm{~kg} / \mathrm{m}^{3}$ arasında üretilen yonga levhaların, aynı yoğunluk aralığında genleșmiş perlit ve vermikülite yakın olan 0.0585-0.0815 W/mK arasında değişen 1 sı iletkenlik değerleri elde edilmiştir. Lertsutthiwong vd. (2008) kağıt mendil imalatından ve mısır kabuğundan elde edilen atık karışımından üretilen düşük termal iletkenliğe sahip yeni yonga levhalar geliştirilmiştir. Karışıma eklenen mısır kabuğu miktarı arttıkça yonga levha yoğunluğunun azaldığını ve nihai ürünün ısı yalıtım performansı artış göstermiştir. Çalışmada, 150-450 kg/m³ arasında yoğunluğa sahip 0.058-0.081 W/mK arasında değișen ısı iletkenlik değerleri elde edilmiştir. Zhou vd. (2004) içi boş buğday samanından düşük yoğunluklu yonga levha geliştirmiştir. Çalışmada, yoğunluğu 100-250 kg/m³ arasında değișen ve yüksek ısı yalıtım performansına sahip yalıtım levhaları elde edilmiştir. Tangjuank (2011) bağlayıcı olarak doğal kauçuk lateks kullanılarak ananas yapraklarından yonga levha geliştirmiştir. Levhalar 20 ve $1.5 \mathrm{~cm}$ kalınlığında olacak şekilde doğal kauçuk lateksin ananas lifi üzerine püskürtülmesi ile üretilmiștir. Levhalar, $210 \mathrm{~kg} / \mathrm{m}^{3}$ yoğunluğu ve $0.035 \mathrm{~W} / \mathrm{mK}$ isı iletkenlik değeri ile yüksek ısı yalıtımı performansı elde edilmiştir. Paiva vd. (2011) mısır koçanı atıklarından 3, 6 ve $8 \mathrm{~cm}$ kalınlığında yonga levhalar geliştirmiştir. Isı iletkenlik değerleri $0.101 \mathrm{~W} / \mathrm{mK}$ levhalar elde edilmiştir. Binici vd. (2011) ısıtma için kullanıldığından çevre için ciddi bir sorun olan ayçiçeği sapı ve anız gibi pamuklu tekstil atıkları ile binaların yalıtımında kullanılmak üzere 30x40x2.5 cm dikdörtgen bloklar, basınç altında hazırlanmıştır. 
Bağlayıcı olarak epoksi kullanılarak üretilen blokların yoğunluklarına bağlı olarak 0.0728-0.2616 W/mK arasında ısıl iletkenlik değerleri elde edilmiştir. Organik kökenli atıklar kullanılarak inşaat sektöründe kullanılabilecek ısıl iletkenliği düşük yalıtım malzemeleri üretilebileceği ortaya konmuştur.

Yalınkılıc vd. (1998) çay yapraklarının yüksek fenolik ekstrakt içeriğinin ve çay üreten fabrikalarda atık olarak bolluğunun faydalanılarak yonga levha üretiminde kullanılması konusunda çalışmalar yapmıştır. Atık çay yaprakları ile üretilen yonga levhanın yüksek fenolik ekstrakt içeriği nedeniyle biyolojik bozulmalara karşı daha dirençli olması beklenmektedir. Levhanın üretimi sırasında bağlayıcı olarak üre formaldehit reçinesi kullanılmıştır. Üretilen levhaların test edilmiş fiziksel ve mekanik özellikleri standart değerleri karşıladığı görülmüştür. Bir dizi uygulama ile genellikle poli ahşap veya fenolik reçineyle bağlanmış ahşap-çimento levhalar, sağlam, hava koşullarına dayanıklı ve maliyeti düşük panel ürünü oluşturma potansiyeline sahiptir (Anonymous, 1974). Ancak, ahşap-çimento levha gelişimi bağlanma ile ilgili mekanizmalarda temel anlayış farklılıkları nedeniyle kısmen yavaşlamıștır (Sandermann ve Kohler, 1964; Takano vd., 1977).

\section{4. Çimento Kompozitler (Cement Composites)}

Dünya genelinde tarım, ahşap ve mobilya endüstrileri gibi çeşitli kaynaklardan üretilen çok miktarda lignoselülozik atık, çevresel kaygılara yol açmaktadır. Bu atıkların çimentolu yapı malzemelerin üretiminde kullanılması sorunların çözümüne katkı sağlayabilir (Karade, 2010). Üretiminde kavak ağacı ile plastiğin kullanılarak üretilen ahşap- plastik kompozitler, düşük maliyet, atık geri dönüşümü, çevre dostu ve düşük karbon ayak izi gibi çok önemli özelliklere sahiptir. Ahşap- plastik kompozitler standart mekanik ve fiziksel özellikleri karşılayarak önemli kullanım potansiyeli oluşturması beklenmektedir (Özyurt, 2020).

Beton, harç ve çimento hamuruna lif takviyesinin dâhil edilmesi, malzemelerin kırılma tokluğu, eğilme mukavemeti ve yorulma direnci, darbe dayanımı, termal şok direnci gibi temel mühendislik özelliklerinin çoğunu geliştirebilir. Son yıllarda, doğal elyaf takviyeli, çimento esaslı kompozitlerin potansiyel uygulamaları dünya genelinde büyük ilgi görmektedir. Birçok ülkede sisal, hindistancevizi, jüt, bambu ve ahşap lifleri gibi doğal liflerle takviye edilmiş çimento esaslı matrislerin çeşitli mekanik özellikleri, fiziksel performansı ve dayanıklılı̆̆ı konusunda araştırmalar yapılmıştır (Tolêdo vd., 1999). Bitki bazlı doğal lifler, hafif, aşındırıcı olmayan, toksik olmayan ve biyolojik olarak parçalanabilir yapıları nedeniyle geleneksel sentetik liflere göre büyük bir avantaja sahiptir. Bambu lifi nispeten yüksek mukavemete, dar mikrofibril açısına ve düşük maliyete sahiptir ve polimer matriks kompozitlerde takviye olarak etkili bir şekilde kullanılabilir, sentetik liflerin bir dereceye kadar yerini alır (Liu vd., 2010).

Pereira vd. (2013) çimentolu matris için takviye olarak hindistancevizi kabuğu lifinin kullanılmasını ve PC'nin PK ile kısmen ikamesini değerlendirmiştir. Karışımlardan biri hindistancevizi lifleri olmadan referans numunesi olmak üzere, ağırlıkça \%5 hindistancevizi lifi ve PC'ye \%0, \%30, \%40 ve \%50 oranlarda PK ile ikame edilmiştir. Hızlandırılmış yaşlanma testlerine tabi tutulan kompozit levhada hindistancevizi lifinin kompozit levhanın yoğunluğunu azalttığı ve mekanik performansı geliştirdiği belirlenmiştir. Zhu vd. (1994) muz lifi takviyeli çimento kompozitlerin üretimi, fiziksel ve mekanik özellikleri araștırılmıştır. Muz lifi ile 20 MPa'dan fazla eğilme dayanımına sahip kompozit ürünler üretilmiştir. Sisal bitkisi, halat, kilim ve çimento kompozitlerin üretiminde kullanılan, büyük miktarda artık üreten önemli bir tarım ürünüdür. Atıklarını değerlendirmek içim; Lima vd. (2014) sisal lifinin çimento kompozitlerin takviyesinde kullanım potansiyelini araştırmışlardır. Sonuçlar, kompozitlerin doğal sisal liflerle takviye edilmesi halinde, geleneksel kompozit ürünlerden daha üstün mekanik özelliklere sahip kompozit malzemelerin üretilebileceğini göstermektedir. Chatveera vd. (2005) çatı malzemesi olarak sisal elyaf takviyeli çimento kompozitinin kullanılmasının araştırmayı amaçlamaktadır. Test sonuçları, sisal elyaf çatı kaplama levhaları için elde edilen bükülme direnci normal çatı kaplama levhalarından daha azdır. Ancak sisal elyaf çatı kaplama levhaları düşük maliyetiyle geçirimsizlik ve yangına dayanıklılık özellikleri gösterir ve yeterli dayanıklılığa sahiptir. Khorami ve Ganjian (2011) çimento kompozitlerin üretiminde Tarımsal Atık Liflerinin (TAL) kullanımı araştırmıştır. Çimento kompozitleri üretmek için PC ağırlıkça \%2 ve \%4 oranında küspe, buğday ve okaliptüs lifleri ilavesi ile üç farklı TAL kullanılmıştır. Ayrıca, silis dumanının çimento kompozitlerin eğilme davranışı özellikleri üzerindeki etkisi de araştırılmıştır. Sonuçlar, çimento kompozitlerin eğilme davranışını liflerin tipine, uzunluğuna, çapına, en boy oranına ve dokusuna bağlı olduğunu ve lif takviyesinin tüm gruplar için eğilme mukavemetini artırdığını göstermektedir. Ayrıca, silis dumanı tüm gruplar için eğilme mukavemetini artırmıştır. Yapılan çalışmalar tarımsal atık liflerin ticari olarak alternatif lif kaynağı olarak kullanılabileceği belirlenmiştir.

\section{Duvar Malzemeleri Üretiminde Kullanılabilirliği (Usability in the Production of Wall Materials)}

Tuğla, blok gibi ürünlerin yalıtım kapasitesini artırmanın yolu kil bünyede gözeneklilik oluşturmaktır. Hem gözenekliliği artırmak hem de atıkları değerlendirmek amacıyla; Demir (2006) işlenmiş atık çayın (İAÇ) kil 
tuğladaki kullanım potansiyelini, dayanıklılık ve mekanik özelliklerine etkilerini araştırmıștır. Ham tuğla kiline farklı oranlarda (ağırlıkça \%0, \%2,5, \%5) İAÇ eklenmiştir. Sonuç olarak, İAÇ'nin düşük maliyetli ve çevre korumasından faydalanarak yapı tuğlalarında kullanılabileceği sonucuna varılmıştır. Demir (2008) kil tuğlalarında da talaş, tütün artıkları ve çim çeşitli organik atıkların kullanım potansiyelini araştırmıştır. Ham tuğla kiline farklı oranlarda (ağırlıkça \%0, \%2,5, \%5, \%10) organik atıklar ilave edilerek pişmiş kil bünyede gözenek oluşturma etkisi incelenmiştir. Organik atıkların kil bünyede gözenek oluşturma için etkili olduğu ve tuğlanın kabul edilebilir mekanik özellikleri koruduğu gözlenmiştir. Sonuç olarak, talaş, tütün artıkları ve çim, tuğla gözenek olușturucu ajanlar olarak çevre açısından güvenli bir șekilde kullanılabileceği görülmüștür. Agbede ve Joel (2011) PK, kil tuğlasının pişmiş özellikleri üzerindeki etkilerini araştırmak için bir çalışma yapmıştır. Ağırlıkça \%2-10 oranlarında PK, kile ilave edilerek üretilen örnekler $800{ }^{\circ} \mathrm{C}^{\prime}$ de pişirilmiştir. PK oranı arttıkça plastisitenin azaldığı, buna karşı \%2 PK ilavesi ile $18.64 \mathrm{~N} / \mathrm{mm}^{2}$ basınç mukavemetine ve \% 14,8 su emme değeri elde edilmiştir. Benzer bir çalışmada, Khedari vd. (2004) PK ilavesi ile üretilen tuğlalar ile $2.1 \mathrm{~N} / \mathrm{mm}^{2}$ basınç dayanımı elde etmiştir. Demir vd. (2005) odun, saman ve sazlardan üretilen kraft hamuru artıklarının kil tuğladaki kullanım potansiyelini ve kil gövdesinde gözenek oluşturma yeteneğini araștırmıștır. Ham tuğla kiline farklı oranlarda (ağırlıkça \%0, \%2,5, \%5, \%10) organik atıklar karıştırılmıştır. \%2,5 ve \%5 atık ilavesinin kabul edilebilir mekanik özelliklere sahip ve kil gövdesinde gözenek oluşturma için etkili olduğu görülmüştür.

Mahmoud vd. (2012) yer fistığı kabuğu külü (YKK) kullanılarak, çimentoya ikame olarak beton blok üretimini araștırmıştır. Çimento YKK ile farklı oranlarda (ağırlıç̧a \%0, \%10, \%20, \%30, \%40, \%50) yer değiștirilmiştir. Beton blokların basınç mukavemetinin $0.26-4.50 \mathrm{~N} / \mathrm{mm}^{2}$ arasında değiștiği ve ikame oranı \%20 oranında elde edilen $3.58 \mathrm{~N} / \mathrm{mm}^{2}$ basınç değerinin Nijerya Endüstri Standardını sağladığı görülmüştür. Oyetola ve Abdullahi (2006) PK kullanılarak üretilen beton blokların basınç dayanımı araştırılmıştır. PÇ, PK ile farklı oranlarda (ağırlıkça \%0, \%10, \%20, \%30, \%40, \%50) ikame edilmiştir. Yüksek ikame oranlarında beton blokların basınç dayanımı standartların altında olduğu, buna karşı \% 20'lik ikamenin optimum bir değiştirme seviyesi olduğu belirlenmiştir. Pinto vd. (2012) agrega olarak granül mısır koçanı kullanılarak hafif bir beton üretilmiştir. Elde edilen sonuçlar, önerilen mısır koçanı betonunun, yapısal olmayan uygulama amaçları için hafif bir beton için gerekli olan yeterli malzeme özelliklerine $\left(382.2 \mathrm{~kg} / \mathrm{m}^{3}\right.$ yoğunluk, $120.0 \mathrm{kN} / \mathrm{m}^{2}$ basınç dayanımı) sahip olabileceği göstermiştir. Sooksaen vd. (2018) Tayland'daki tarım endüstri atıklarından elde edilen mısır kabuğu lifi, küspe lifi ve hindistancevizi kabuğu lifi kullanarak hafif beton blok geliştirmiştir. Kütlece \%30 kadar hindistancevizi kabuğu lifi kullanılarak optimum mekanik özelliklerde hafif beton blok elde edilmiştir. Sobuz vd. (2014) Malezya'da tropik bölgelerde katı atık türü olan Palmiye Yağı Kabuğu (PYK) farklı karışım oranlarıyla, hafif agrega olarak \%0-50 arasında betona ilave edilerek üretilen hafif betonun dayanım ve maliyet analizi yapılmıştır. Hafif betonun basınç dayanımının PYK yüzdesi arttıkça azaldığı, buna karşı \%15'e varan olası maliyet düşüşünü göstermiştir. PYK kullanımının hafif beton üretiminde büyük potansiyele sahip olduğu sonucuna varılmıştır.

\section{6. Çimento Harçlar Üretiminde Kullanımı (Use of cement mortar production)}

Sangeetha (2016) harç karışımlarında, pirinç kabuğu külünün (PK) çimento ile \%10-40 oranlarda ikame edilerel harç özelliklerine etkisini araştırmıştır. Araştırma sonucunda, PK günümüzde üretilen çimento beton bloklardan daha ekonomik ve çevre dostu olduğu ve yapı malzemesi üretiminde kullanılabileceği öne sürülmüştür. Chatveera ve Lertwattanaruk (2009) harç karışımlarında, su-bağlayıcı oranları 0.55 ve 0.65 olan PK çimento ile belirli oranlarda (\%10, \%30,\%50) ikame edilmesinin beton özelliklerine etkisi araștırılmıştır. Harcın sülfat saldırısı dayanımını ölçmek için \%5 sodyum sülfat $\left(\mathrm{Na}_{2} \mathrm{SO}_{4}\right)$ ve magnezyum sülfat $\left(\mathrm{MgSO}_{4}\right)$ çözeltileri kullanılmıştır. Çalışmada, PK'nın betonda puzolanik bir malzeme olarak uygulanabileceğini ve sodyum sülfat saldırısına karşı direnci geliştirebileceğini, ancak magnezyum sülfat saldırısına karşı direnci azaltabileceğini öne sürülmüştür. Duggal vd. (2020) çimento harcı kullanılarak üretilen çatı kiremitlerinin, PK ve ŞKK ayrı ayrı çimento ile belirli oranlarda (\%10, \%15, \%20) ikame edilmesinin beton özelliklerine etkisi araștırılmıștır. Araştırmada, PK ve ŞKK çimento ile ikame edilerek çatı kiremitlerinin üretimi için çevreci bir potansiyele sahip olduğunu göstermiştir. Chindaprasirta vd. (2008) harç karışımlarında, 0.5 su-bağlayıcı oranı olan PYK, PK ve UK çimento ile belirli oranlarda (\%20, \%40) ikame edilmesinin, betonun klorür penetrasyonuna karşı etkisi araștırılmıştır. Harç karışımlara, \%3 NaCl harç çözeltisine 30 günlük daldırmadan sonra basınç dayanımı, hızlı klorür penetrasyon testi, hızlı geçirgenlik testi ve klorür penetrasyon derinliği incelenmiştir. Test sonuçları, harcın klorür penetrasyonuna karşı direncin, PYK, PK ve UK ile ikame edilmesi ile önemli ölçüde iyileştiğini göstermektedir. Canovas vd. (1992) çimento harçlarında bitkisel lif mineralizasyonu problemini çözmek için sisal elyaf kullanarak çalışma yürütmüştür. Kullanılan ürünler, harcın alkalilik derecesini azaltmada, harç gözeneklerini kapatmada ve liflerde su emiliminde azaltmada etkinlik göstermektedir. Kullanılan katkı maddelerinin alkalinite azaltma gücü, özellikle alkali reaktif agregalarla yapılan betonların dayanıklılığı için yeni araştırmalara konu olması beklenir. 


\section{Tartışma ve Sonuç (Results and Discussion)}

Betonun ana bileșeni olan Portland Çimentosunun Dünya'daki yıllık üretimi 4.5 Milyar ton civarında olup kitlesel üretimde ön sıralarda yer almaktadır. PÇ’nin üretimi, önemli miktarda sera gazı olan $\mathrm{CO}_{2}$ salınımına yol açar; bir ton PÇ’nin üretiminde yaklaşık bir ton $\mathrm{CO}_{2}$ ve diğer sera gazları üretilmektedir. Organik kökenli atıkların, çimentoya belirli oranlarda ikame olarak kullanılabileceği yürütülen çalışmalarla ortaya konmuştur. Bu atıkların çimento ikamesi olarak beton ve beton ürünlerin üretiminde kullanılması ile önemli çevresel ve ekonomik faydalar sağlanabilecektir. Bu uygulamalar çimento üretiminde azalma sağlarken, hem karbon salınımını azaltacak hem de atıkların doğal çevreye vereceği zararlar önemli ölçüde engellenecektir. Yürütülen çalışmalarda organik atıkların önemli bir selüloz kaynağı olması ve selülozunda çimento matrisini güçlendirmesine olan etkisi nedeniyle çimento kompozitlerde sıkça tercih edilmektedir. Organik kökenli atıkların hafif beton üretimi, duvar blokları üretimi, yalıtım malzemeleri üretimi, tuğla, kiremit vb. üretiminde katkı olarak kullanılması ile bu atıkların yeniden kullanımı ve geri kazanımı sağlanarak çevreci malzemelerin üretilmesi yaygınlaşacaktır.

\section{Çıkar Çatışması (Conflict of Interest)}

Yazarlar tarafından herhangi bir çıkar çatışması beyan edilmemiştir. No conflict of interest was declared by the authors.

\section{Kaynaklar (References)}

Agbede, I.O., Joel, M., 2011. Effect of rice husk ash (RHA) on the properties of Ibaji burnt clay bricks. American Journal of Scientific and Industrial Research, 2, 674-677.

Akeke, G.A., Ephraim, M.E. and Ukpata, J.O., 2013. Structural properties of rice husk ash concrete. International Journal of Engineering and Applied Sciences, 3, 57-62.

Alabadan, B.A., Olutoye, M.A., Abolarin, M.S. and Zakariya, M., 2005. Partial replacement of Ordinary Portland Cement (OPC) with Bambara Groundnut Shell Ash (BGSA) in concrete. Leonardo Electronic Journal of Practices and Technologies, 6, 4348.

Anonymous, N.D., 1974. Wood-Cement Building Boards, Bison System Board Plants, Bison-Werke, Springer, W. Germany.

Aprianti, E., Shafigh, P., Bahri, S., Farahani, J.N., 2015. Supplementary cementitious materials origin from agricultural wasteseA review, Constr. Build. Mater. 74, 176-187.

Baluch, H., Ziraba, Y.N., Azad, A.K., 1987. Fracture characteristics of sisal fibre reinforced concrete. The International Journal of Cement Composites and Lightweight Concrete, 9, 157-168.

Binici, H., Eken, M., Dolaz, M., Aksogan, O., Kara, M., 2014. An environmentally friendly thermal insulation material from sunflower stalk, textile waste and stubble fibres. Construction and Building Materials, 51, 24-33.

Binici, H., Yucegok, F., Aksogan, O., Kaplan, H.., 2008. Effect of corncob, wheat straw and plane leaf ashes as mineral admixtures on concrete durability. ASCE, Civ Eng Mater., 20, 478-483.

Bolat, M., 2005. Use of biomass sources for energy in Turkey and a view to biomass potential. Biomass Bioenergy, 29, $32-41$.

Buari, T.A., Ademola, S.A. and Ayegbokiki, S.T., 2013. Characteristics Strength of groundnut shell ash (GSA) and Ordinary Portland cement (OPC) blended Concrete in Nigeria. IOSRJEN, 3, 1-7.

Canovas, M.F., Selva, N.H., Kawiche, G.M., 1992. New economical solutions for improvement of durability of Portland cement mortars reinforced with sisal fibres. Materials and Structures, 25, 417-422.

Chatveera, B., Lertwattanaruk, P., 2009. Evaluation of sulfate resistance of cement mortars containing black rice husk ash. Journal of Environmental Management, 90, 1435-1441.

Chatveera, B., Nimityongskul, P., Tansriprapasiri, W., Seehabuth, P., 2005. Development of sisal fiber reinforced roofing sheets. AGRIS, 4, 44-61.

Chindaprasirta, P., Homwuttiwongb, S., Jaturapitakkulb, C., 2007. Strength and water permeability of concrete containing palm oil fuel ash and rice husk-bark ash. Construction and Building Materials, 21, 1492-1499.

Chindaprasirta, P., Rukzona, S., Sirivivatnanonb, V., 2008. Resistance to chloride penetration of blended Portland cement mortar containing palm oil fuel ash, rice husk ash and fly ash. Construction and Building Materials, 22, 932-938.

Cook, D.J., 1984. Development of microstructure and other properties in rice husk ash-OPC systems. Australasian Conference on the Mechanics of Structures and Materials, 9th, 1984, Sydney, Australia, 355-360.

Çimento Sektörü Raporu, 2018. Sanayi ve Verimlilik Genel Müdürlüğü Sektörel Raporlar Ve Analizler Serisi, Çimento Raporu.

Demir, İ., 2006. An investigation on the production of construction brick with processed waste tea. Building and Environment, 41, 1274-1278.

Demir, I., Baspınar M.S. and Orhan M., 2005. Utilization of kraft pulp production residues in clay brick production. Building and Environment, 40, 1533-1537.

Demir, İ., 2008. Effect of organic residues addition on the technological properties of clay bricks. Waste Management, 28, 622627.

Demirbas, A. and Aslan, A., 1998. Effects of ground hazelnut shell, wood, and tea waste on the mechanical properties of cement. Cement and Concrete Research, 28, 1101-1104.

Duggal, P., Yadav, B., Choudhry H., Springer, A. G. 2020. Comparative Analysis of Cement Mortar Roof Tiles Using Agricultural Waste. Nature Singapore Pte, Advances in Structural Engineering and Rehabilitation, Lecture Notes in Civil Engineering.

Gündüzalp, A.A., Güven, S., 2016. Atık, Çeşitleri, Atık Yönetimi, Geri Dönüşüm ve Tüketici: Çankaya Belediyesi ve Semt Tüketicileri Örneği. Hacettepe Üniversitesi Sosyolojik Araştırmalar E-Dergisi. 
Gürel B., 2020. Türkiye'deki güncel biyokütle potansiyelinin belirlenmesi ve yakılmasıyla enerji üretimi iyi bir alternatif olan biyokütle atıklar için sektörel açıdan ve toplam yanma enerji değerlerinin hesaplanması, Mühendislik Bilimleri ve Tasarım Dergisi 8(2), 407 - 416.

James, J., Rao, M.S., 1986. Reactivity of rice husk ash. Cement and Concrete Research, 16, 296-302.

James, J., Rao, M.S., 1986. Characterization of silica in rice husk ash. American Ceramic Society Bulletin, 65, 1177-1180.

Karade, S.R., 2010. Cement-bonded composites from lignocellulosic wastes. Construction and Building Materials, 24, 13231330.,

Kartalkanat, A., 2010. Çimento fabrikalarının çevreye muhtemel etkileri, online website. İnternet erişimi: http://www.ovamadokunma.com/index.php/makaleler/okuyucu-makaleleri/105-cimento-fabrikalarnn-cevreyemuhtemel-etkileri

Khabir, L., Huda, M., Amin, R., Kamruzzaman, S., 2013. Energy Saving Brick from Rice Husk Ash. International Conference Mechanical, Industrial and Materials Engineering, Rajshahi, Bangladesh, 222-226.

Khan R., Jabbar A., Ahmad I., Akhtar Naeem Khan A. N., 2012. Reduction in environmental problems using rice-husk ash in concrete, Constr. Build. Mater. 30, 360-365

Khedari, J., Nankongnab, N., Hirunlabh, J. and S. Teekasap 2004. New low-cost insulation particleboards from mixture of durian peel and coconut coir. Building and Environment, 39, 59-65.

Khorami, M. and Ganjian E., 2011. Comparing flexural behaviour of fibre-cement composites reinforced bagasse: Wheat and eucalyptus. Construction and Building Materials, 25, 3661-3667.

Kishore, R., Bhikshma V. and Prakash P.J., 2011. Study on Strength Characteristics of High Strength Rice Husk Ash Concrete. Procedia Engineering, 14, 2666-2672.

Kraiwood, K., Chai, J., Smith, S., Seksun, C., 2001. A study of ground coarse fly ashes with different finenesses from various sources as pozzolanic materials. Cement and Concrete Composites, 23, 335-343.

Le H.T., Nguyen S.T.,. Ludwig H.-M., 2014. A study on high performance fine-grained concrete containing rice husk ash, International Journal of Concrete Structures and Materials 8 (4), 301-307.

Lertsutthiwong, P., Khunthon, S., Siralertmukul, K., Noomun, K. and Chandrkrachang, S., 2008. New insulating particleboards prepared from mixture of solid wastes from tissue paper manufacturing and corn peel. Bioresource Technology, 99, 48414845.

Lima, P.R.L., Santos, R.J., Ferreira, S.R. and Tolêdo, F.R.D., 2014. Characterization and treatment of sisal fiber residues for cement-based composite application. Engenharia Agrícola, 34, 812-825.

Liu, D., Song, J.,Debbie, P. A., Peter, R. C. and, Yan, H., (2012), Bamboo fiber and its reinforced composites: structure and properties, Cellulose 19:1449-1480

Mahmoud, H., Belel, Z.A. and Nwakaire, C., 2012. Groundnut shell ash as a partial replacement of cement in sandcrete blocks production. International Journal of Development and Sustainability, 1, 1026-1032.

Malhotra, V.M., Mehta, P.K., 2004. Pozzolanic and cementitious materials. Advances in concrete technolog, Gordon and Breach Science Publishers.

Mehta, P.K., 1978. Siliceous ashes and hydraulic cements prepared therefrom. US Patent 4105459A.

Mehta, P.K., Folliard, K.J., 1995. Rice-husk ash-a unique supplementary cementing material. Materials Science, 154, 531-542.

Nwofor, T.C. and Sule, S., 2012. Stability of groundnut shell ash (GSA)/ordinary portland cement (OPC) concrete in Nigeria. Advances in Applied Science Research, 3, 2283-2287.

Oyetola, E. B. and Abdullahi, M., 2006. The Use of Rice Husk Ash in Low-Cost Sandcrete Block Production. Leonardo Electronic Journal of Practices and Technologies, 8, 58-70.

Öner, M.N.K., 2019. Tarım Atıklarının Geri Dönüștürülmesi: Yalova İli Tarımsal Atık Yönetimi, Mühendislikte Yeni Yaklașımlar, s 86-97.

Özyurt, H . 2020. Design and properties of composite sustainable building material by using waste (HDPE). Mühendislik Bilimleri ve Tasarım Dergisi , 8 (3), 777-782.

Paiva, A., Pereira, S., Sá. A., Cruza, D., Varum, H. and Pinto, J., 2012. A contribution to the thermal insulation performance characterization of corn cob particleboards. Energy and Buildings, 45, 274-279.

Pappua, A., Saxenaa, M., Asolekarb, S.R., 2007. Solid wastes generation in India and their recycling potential in building materials. Building and Environment, 42, 2311-2320.

Paya, J., Monzo, J., Peris-Mora, E., Borrachero, M.V., Tercero, R., Pinillos, C., 1995. Early-strength development of Portland cement mortars containing air classified fly ashes. Cement and Concrete Research, 25, 449-456.

Paya, J., Monzo, J., Borrachero, M.V., Peris, E., Gonzalez-Lopez, E., 1997. Mechanical treatment of fly ashes. Part III: studies on strength development on ground fly ash cement mortars. Cement and Concrete Research, 27, 1365-1377.

Pereira, C.L., Savastano, H.Jr., Payá, J., Santos, S.F., Borrachero, M.V., Monzó, J. and Soriano, L., 2013. Use of highly reactive rice husk ash in the production of cement matrix reinforced with green coconut fiber. Industrial Crops and Products, 49, 88-96.

Pinto, J., Vieira, B., Pereira, H., Jacinto, C., Vilela, P., Paiva, A., Pereira, S., Cunha, V.M.C.F. and Varum H., 2012. Corn cob lightweight concrete for non-structural applications. Construction and Building Materials, 34, 346-351.

Pone, J., Ash, A., Kamau, J. and Hyndman, F., 2018, Palm Oil Fuel Ash as A Cement Replacement in Concrete. Modern Approaches on Material Science, 1, 4-8.

Reddy, S., Reddy, R. and Songkasupa, P., 2018. Evaluation of Mechanical Properties of Cement Concrete Pavement Using Granite Dust and Baggage Ash. International Journal of Applied Engineering Research, 13, 187-192.

RILEM Committee 73-SBC, 1988. Final report: siliceous by-products for use in concrete. Materials and Structures, 21, 69-80. Sandermann W. and Kohler, R., 1964. Holzforschung 18, 53.

Sangeetha, S. P., 2016. Rice Husk Ash Sandcrete Block as Low Cost Building Material. Int. Journal of Engineering Research and Application, 6, 46-49.

Saraswathy, V. and Song, H., 2007. Corrosion performance of rice husk ash blended concrete. Construction and Building Materials, 21, 1779-1784. 
Sensale, G.R., 2006. Strength development of concrete with rice-husk ash. Cement \& Concrete Composites, 28, 158-160.

Sobuz, H. R., Hasan, N. Md. S., Tamanna, N. and Islam, S. 2014. Structural Lightweight Concrete Production by Using Oil Palm Shell. Hindawi Publishing Corporation Journal of Materials, 2014, 1-6.

Sooksaen, P., Boodpha, V., Janrawang, P. and Songkasupa, P., 2018. Fabrication of Lightweight Concrete Composites Using Natural Fibers in Thailand. Engineering Materials, 765, 305-308.

Takano, R., Kayahara, M. and Nakagawa, H., 1977. Fukui-Ken Mokuzai Shikenjo 31, 1.

Tangchirapat, W., Saeting, T., Jaturapitakkul, C., Kiattikomol, K., Siripanichgorn, A., 2007. Use of waste ash from palm oil industry in concrete. Waste Management, 27, 81-88.

Tangjuank, S., 2011. Thermal insulation and physical properties of particleboards from pineapple leaves. International Journal of Physical Sciences, 6, 4528-4532.

Tolêdo, F.R.D., Kuruvilla J., Khosrow G. and England, G.L., 1999. The use of sisal fibre as reinforcement in cement based composites. Revista Brasileira de Engenharia Agrícola e Ambiental, 3, 245-256.

Xu, J.Y., Sugawara, R., Widyorini, R., Han, G.P. and Kawai, S., 2004. Manufacture and properties of low-density binderless particleboard from kenaf core. Journal of Wood Science, 50, 62-67.

Yalinkilic, M.K., Imamura, Y., Takahashi, M., Kalaycioglu, H., Nemli, G., Demirci, Z., Ozdemir, T., 1998. Biological, physical and mechanical properties of particleboard manufactured from waste tea leaves. International Biodeterioration \& Biodegradation, 41, 75-84.

Yashwanth, M.K. and Nagarjuna, P., 2016. An Experimental Study on Synergic Effect of Sugar Cane Baggage Ash and Fly Ash in Concrete. International Journal for Innovative Research in Science \& Technology, 3, 174-178.

Yoshizawa, S., Tanaka, M., Shekdar, A.V., 2004. Global trends in waste generation. Recycling, waste treatment and clean technology, 1541-1552.

Zhou, X., Zheng, F., Li, H. and Lu, C., 2010. An environment-friendly thermal insulation material from cotton stalk fibers. Energy and Buildings, 42, 1070-1074.

Zhou, X.Y., Li, J. and Zhou, D.G., 2004. Thermal transfer properties of low density wheat strawboard. Journal of Nanjing Forestry University, 28, 1-4.

Zhu, W.H., Tobias, B.C., Coutts, R.S.P. and Langfors, G., 1994. Air-Cured Banana-Fibre-Reinforced Cement Composites. Cement \& Concrete Composites, 16, 3-8. 